\title{
CORRIGENDUM
}

\section{Regulation of microRNA expression by HMGA1 proteins}

I De Martino, R Visone, M Fedele, F Petrocca, D Palmieri, JM Hoyos, F Forzati, CM Croce and A Fusco

Oncogene (2016) 35, 5817-5818; doi:10.1038/onc.2016.136; published online 11 July 2016

Correction to: Oncogene (2009) 28, 1432-1442; doi:10.1038/onc. 2008.495; published online 26 January 2009

The following figure is provided to replace Figure $6 \mathrm{~b}$. The corresponding author would like to highlight that that these results are confirmed by the experiment shown in Figure 7 of the published paper, showing that the $3^{\prime}$-UTR of HMGA2 is negatively regulated by miR-196a-2, and thus proving the regulation of HMGA2 by miR-196a-2.
The author would like to mention that the ability of miR-196a-2 to knock down HMGA2 has been subsequently confirmed in another paper published by his group: Palmieri D, D'Angelo D, Valentino T, De Martino I, Ferraro A, Wierinckx A et al. Downregulation of HMGA-targeting microRNAs has a critical role in human pituitary tumorigenesis. Oncogene 2012; 31: 3857-3865. 


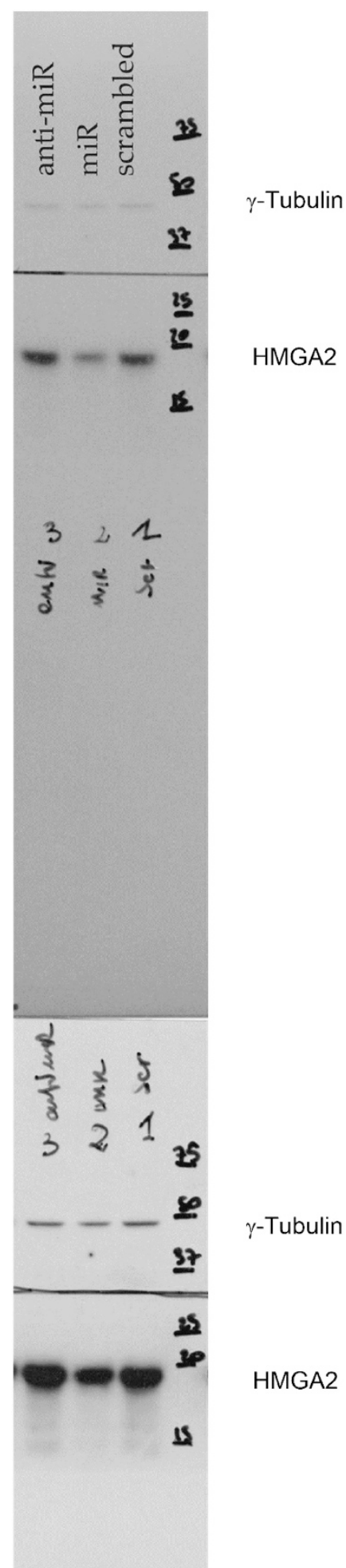

Figure 6. (b) Western blot for the HMGA2 expression after treatment of the cells with the scrambled oligonucleotide, miR-196a-2 and antimiR-196a-2. The lanes have been loaded from left to right: NIH 3 T3 cells transfected with antimiR-196a-2; NIH 3T3 cells transfected with miR-196a-2; NIH 3T3 cells transfected with the scrambled oligonucleotide, respectively. The same western blot was also stained with antibodies against gamma tubulin used as a loading control. Upper: low exposure; lower: high exposure. 